ARTICLE

https://doi.org/10.1038/s41467-019-14170-6

\title{
Nanoelectrode design from microminiaturized honeycomb monolith with ultrathin and stiff nanoscaffold for high-energy micro- supercapacitors
}

\author{
Zhendong Lei ${ }^{1,2,5}$, Long Liu ${ }^{1,5}$, Huaping Zhao ${ }^{1 \star}$, Feng Liang (10) ${ }^{3 \star}$, Shilei Chang ${ }^{3}$, Lei Li ${ }^{4}$, Yong Zhang (10 ${ }^{2}$, \\ Zhan Lin ${ }^{4 \star}$, Jörg Kröger (1D ${ }^{1} \&$ Yong Lei (i) ${ }^{1 *}$
}

Downsizing the cell size of honeycomb monoliths to nanoscale would offer high freedom of nanostructure design beyond their capability for broad applications in different fields. However, the microminiaturization of honeycomb monoliths remains a challenge. Here, we report the fabrication of microminiaturized honeycomb monoliths-honeycomb alumina nanoscaffold-and thus as a robust nanostructuring platform to assemble active materials for microsupercapacitors. The representative honeycomb alumina nanoscaffold with hexagonal cell arrangement and $400 \mathrm{~nm}$ inter-cell spacing has an ultrathin but stiff nanoscaffold with only $16 \pm 2 \mathrm{~nm}$ cell-wall-thickness, resulting in a cell density of $4.65 \times 10^{9}$ cells per square inch, a surface area enhancement factor of 240 , and a relative density of 0.0784 . These features allow nanoelectrodes based on honeycomb alumina nanoscaffold synergizing both effective ion migration and ample electroactive surface area within limited footprint. A microsupercapacitor is finally constructed and exhibits record high performance, suggesting the feasibility of the current design for energy storage devices.

\footnotetext{
${ }^{1}$ Institute of Physics and IMN MacroNano ${ }^{\circledR}$, IImenau University of Technology, IImenau, Germany. ${ }^{2}$ NUS Graduate School for Integrative Sciences and Engineering, National University of Singapore, Singapore, Singapore. ${ }^{3}$ Faculty of Metallurgical and Energy Engineering, Kunming University of Science and Technology, Kunming, China. ${ }^{4}$ School of Chemical Engineering and Light Industry, Guangdong University of Technology, Guangzhou, China. ${ }^{5}$ These authors contributed equally: Zhendong Lei, Long Liu. *email: huaping.zhao@tu-ilmenau.de; liangfeng@kust.edu.cn; zhanlin@gdut.edu.cn; yong.lei@tu-ilmenau.de
} 
$\mathrm{H}$ oneycomb monoliths (HMs) are a kind of cellular materials with two-dimensional cell configuration consisting of parallel and straight channels extended throughout the body ${ }^{1}$. HMs have been widely exploited as catalyst supporters in different gaseous reactor applications such as chemical and refining processes, catalytic combustion, ozone abatement, and photocatalytic air purification ${ }^{2-7}$. As catalyst supporters, HMs have higher surface-to-volume ratio comparing to that of planar substrates for providing high contact efficiencies between the supported catalysts and the gaseous reactants, meanwhile their parallel and straight channels facilitate mass transport of gas with low diffusion resistance. Besides these gas-phase catalysis applications, the cellular and homogeneous structure of the HM presents potential opportunities for other functional applications. For example, it could be a desirable platform to assemble an electroactive electrode for electrochemical devices (e.g., batteries, supercapacitors, fuel cells, water electrolyzer, and electrochemical sensors), in which an efficient electrochemical reaction requires both high specific surface area of the electrode and favorable ionic transport within the electrode ${ }^{8-11}$. Despite these merits, so far HMs have not been widely utilized for electrochemical applications mainly due to the bulky structure of the existing HMs. The present electrode design based on HMs makes electrochemical devices cumbersome (especially the device volume), and meanwhile the macrostructural channels of HMs require an impractically large amount of electrolytes to fill up all the channels in order to ensure a sufficient contact between the supported electroactive materials and the electrolyte, which is different from gas-phase catalysis applications. Moreover, the specific surface area of the conventional HMs, although it is higher than that of planar substrate counterparts, is far from sufficient to satisfy the requirements of electrochemical applications. Currently, the best reported HM can only attain $1.6 \times 10^{4}$ cells per square inch (cpsi) and about $3 \mu \mathrm{m}$ in cell wall thickness ${ }^{12}$, with a specific surface area not being comparable with that of widely used nanoelectrodes (i.e., mainly arrays of nanowires or nanotubes). However, most of those nanoelectrodes suffer from the limit of aspect ratio to maintain their highly oriented nature by avoiding the agglomeration since nanowires and nanotubes with high aspect ratio would prefer to form into many dense clusters, and consequently are difficult to simultaneously satisfy both high specific surface area and low ion transport resistance. To this end, downsizing the cell size (e.g., channel diameter and cell wall thickness) of the conventional HMs to nanoscale shall be a solution to efficiently address the challenges for extending the application potentials of HMs. Nevertheless, the microminiaturization of the HMs encounters technological difficulties in creating exactly parallel and straight nanoscale channels over a large area by all reported HM fabrication approaches whatever in industry or in laboratory, and meanwhile faces the challenge to guarantee that the microminiaturized HM would hold the similar excellent mechanical stabilities as the conventional HM.

In this article, microminiaturized HMs with ultrathin and stiff nanoscaffold-honeycomb alumina nanoscaffold (HAN) - is realized for the first time. Specifically, a large-scale HAN is fabricated by using a nanoindentation-anodization-etching process with a high-purity aluminum foil. A representative HAN is actually a microminiaturized HM with hexagonal cell arrangement, $400 \mathrm{~nm}$ inter-cell spacing and only $16 \pm 2 \mathrm{~nm}$ cell wall thickness. Impressively, the cell density of the HAN reaches $4.65 \times 10^{9} \mathrm{cpsi}$ that is five orders of magnitude higher than that of the reported highest value. Meanwhile, the HAN with such ultrathin cell wall is stiff and can sustain surprisingly high mechanical stability identified by an experimental nanoindentation. Such robust HAN offers a stable nanostructuring platform to assemble electroactive materials for micro-supercapacitors
(MSCs). The insulating HAN is retained in the nanoelectrodes and thus endows the nanoelectrodes with vertically aligned and robustly stable nanoporous structure to simultaneously achieve both effective ion migration and ample electroactive surface area within limited footprint. As a result, a MSC constructed with the HAN-based nanoelectrodes exhibits record high-energy performance among the reported micro-supercapacitors. The maximum capacitance of the MSC reaches $128 \mathrm{mF} \mathrm{cm}^{-2}$ at a current density of $0.5 \mathrm{~mA} \mathrm{~cm}^{-2}$, and the peak energy and power densities are $160 \mu \mathrm{Wh} \mathrm{cm} \mathrm{cm}^{-2}$ and $40 \mathrm{~mW} \mathrm{~cm}^{-2}$, respectively.

\section{Results}

Formation and structure of HAN. A schematic of the farbication process of HAN, and the corresponding scanning electron microscope (SEM) images, are shown in Fig. 1a-h. Briefly, the fabrication of HAN includes nanoindentation, anodization, and a two-step etching process (Fig. 1a). The fabrication process begins with the anodization of a surface-nanopatterned aluminum substrate to obtain nanoporous alumina $\left(\mathrm{Al}_{2} \mathrm{O}_{3}\right)$ with a hexagonal cell arrangement and a cell periodicity of $400 \mathrm{~nm}$. Notablely, the as-prepared nanoporous alumina has a double-layer cell structure (Fig. 1b), with an acid acid anion-contaminated $\mathrm{Al}_{2} \mathrm{O}_{3}$ thick layer (in dark-gray color with the thickness of $90 \pm 2 \mathrm{~nm}$ ) adjacent to the cell center and a relatively pure $\mathrm{Al}_{2} \mathrm{O}_{3}$ thin layer (in light-gray color with the thickness of $21 \pm 2 \mathrm{~nm}$ ) remote from the cell center $^{12}$. By applying a precisely controlled two-step etching in aqueous $\mathrm{H}_{3} \mathrm{PO}_{4}$ solutions, the acid anion-contaminated $\mathrm{Al}_{2} \mathrm{O}_{3}$ thick layer are easy to be totally dissolved and meanwhile the pure $\mathrm{Al}_{2} \mathrm{O}_{3}$ thin layer is partially etched. Finally, a honeycomb nanoscaffold consisting of only an ultrathin layer of pure $\mathrm{Al}_{2} \mathrm{O}_{3}$ is left with the cell wall thickness of $16 \pm 2 \mathrm{~nm}$ (Fig. 1c), which is a HAN (i.e., a microminiaturized HM). Figure 1d schematically shows the evolution of the HAN through the second etching process. In the case of the HAN with hexagonal cell arrangement and $400 \mathrm{~nm}$ inter-cell spacing, the cell density is calculated to be $4.65 \times 10^{9} \mathrm{cpsi}$ that is five orders of magnitude higher than that of the reported highest value ${ }^{13}$. The cross-sectional SEM image of a HAN with cell depth of about $25 \mu \mathrm{m}$ confirms the straight and stable nanoporous structure of the HAN (Fig. 1e). Noting that the cell depth of the HAN depends on the anodization time, by tuning the anodization time, the cell depth of the HAN can be adjusted from hundreds of nanometers to hundreds of micrometers. The surface area enhancement factor for an abovementioned HAN with the $25-\mu \mathrm{m}$-deep cell is calculated to be 240 . And, importantly, the relative density of HAN is calculated to be only 0.0784 , corresponding to its porosity of 0.9216 . When applying such HAN as a scaffold for designing electrodes and/or devices, the high specific surface area and the lower "dead volume" (i.e., the proportion of the insulating $\mathrm{Al}_{2} \mathrm{O}_{3}$ to the whole electrode) in electrodes/devices will be simultaneously satisfied, benefiting to accomplishing high device performance. Not limited to hexagonal cell arrangement with $400 \mathrm{~nm}$ inter-cell spacing, two other HANs also have been produced through tuning the nanopatterns on the surface of aluminum foils generated by nanoindentation, one with hexagonal cell arrangement but $800 \mathrm{~nm}$ intercell spacing (Fig. 1f) and the other with $400 \mathrm{~nm}$ inter-cell spacing but square cell arrangement (Fig. 1g). Note that the HAN can be fabricated over large area with almost no structural defects (Fig. 1h and Supplementary Fig. 1a-b), which is also an important advantage of the HAN for electrode designing.

Generally, a compressive stack pressure typically in the range of 0.1-10 MPa is applied during the assembly of batteries (coin- and punch-cell) and supercapacitors for the purpose of maintaining intimate contact between the electrodes and the current collectors as well as preventing active materials delamination and deformation in 


\section{a}
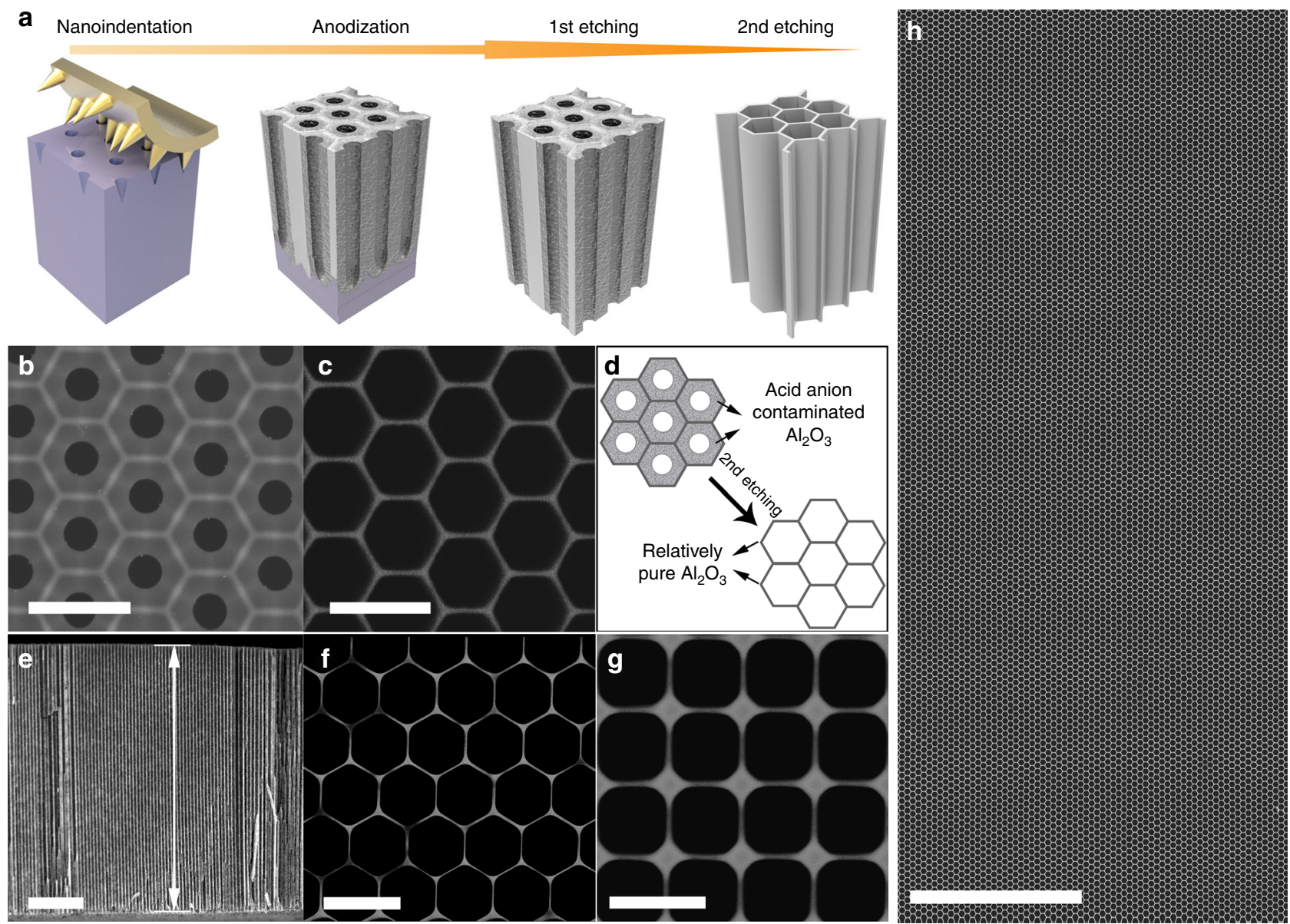

Fig. 1 Fabrication and structure of HAN. a Illustration of the HAN fabrication process. b SEM image of nanoporous alumina after anodization process revealing the double-layer cell structure. c SEM image of HAN with hexagonal cell arrangement and $400 \mathrm{~nm}$ inter-cell spacing showing the structure of HAN with ultrathin wall of $16 \pm 2 \mathrm{~nm}$. d Schematic of the evolution of the HAN by the second etching process. e Cross-sectional view SEM image of an HAN indicating the cell depth to be about $25 \mu \mathrm{m}$. f SEM image of HAN with hexagonal cell arrangement and $800 \mathrm{~nm}$ inter-cell spacing. The wall thickness of the cell is $18 \pm 2 \mathrm{~nm}$. $\mathbf{g}$ SEM image of HAN with square cell arrangement and $400 \mathrm{~nm}$ inter-cell spacing. The wall thickness of the cell is $12 \pm 2 \mathrm{~nm}$. $\mathbf{h}$ Large-scale SEM image showing the uniform, stable and defect-free structure of the HAN with hexagonal cell arrangement and 400 nm inter-cell spacing. Scale bar: $500 \mathrm{~nm}$ (b); $500 \mathrm{~nm}(\mathbf{c}) ; 5 \mu \mathrm{m}(\mathbf{e}) ; 1 \mu \mathrm{m}(\mathbf{f}) ; 500 \mathrm{~nm}(\mathbf{g}) ; 10 \mu \mathrm{m}(\mathbf{h})$.

the electrodes during operation ${ }^{14}$. Obviously, such high extrusion pressure would bring forward the critical challenges and requirements to the mechanical stabilities of the nanoelectrodes for supercapacitors and batteries. As known, the cellular solids with honeycombs are much stiffer and stronger to manifest high compressive strength when loaded at the out-of-plane direction (i.e., along the cell axis) than at the in-plane direction ${ }^{15,16}$, thus nanoindentation experiments have been further conducted for characterizing the nanomechanical properties of the HAN. The Young's modulus of the HAN with hexagonal cell arrangement, $400 \mathrm{~nm}$ inter-cell spacing and only $16 \mathrm{~nm}$ cell wall thickness are obtained in the range of 1.41-3.22 GPa measured at five different positions (Supplementary Fig. 1c). The excellent mechanical performance of the HAN should be attributed to not only the high hardness of the pure $\mathrm{Al}_{2} \mathrm{O}_{3}$ and also the anisotropic honeycomb microarchitectures of the $\mathrm{HAN}^{17-20}$, and it would be a significant advantage when applying as nanostructuring platform to assemble electroactive materials especially for supercapacitors and batteries, because the HAN can play the part of a rigid keel in the nanoelectrodes to sustain the mechanical extrusion during the device assembly but maintain the structural features at the nanoscale of the electrodes, which are inherited from the HAN, for finally accomplishing nanoelectrodes with both high specific surface area and low ion transport resistance for efficient electrochemical energy storage.

Fabrication and characterizations of $\mathrm{HAN} @ \mathrm{SnO}_{2}$ as nanostructured current collectors. As aforementioned, the HAN is a kind of microminiaturized HMs with much higher cell density than the conventional HMs, and the cellular and homogeneous structure of the HAN presents opportunities as nanostructuring platform to assemble electroactive materials for electrochemical devices. Given the insulating nature of the HAN, the first step to design nanoelectrodes with the HAN for electrochemical applications is to convert the insulating HAN to be a nanostructured current collector. As shown in Fig. 2a, a 12-nm-thick tin oxide $\left(\mathrm{SnO}_{2}\right)$ layer was conformally coated onto the HAN with hexagonal cell arrangement and $400 \mathrm{~nm}$ inter-cell spacing (Fig. 1c) through atomic layer deposition (ALD). Note that a thick layer of nickel $(\sim 10 \mu \mathrm{m})$ as the supporting substrate was electrochemically deposited onto the top of the HAN before the conduction of the ALD process. The $\mathrm{SnO}_{2}$-coated $\mathrm{HAN}$ (denoted as $\mathrm{HAN}_{\mathrm{SnO}}$ ) preserves the original honeycomb features with the cell wall thickness increasing from $16 \pm 2$ to $40 \pm 2 \mathrm{~nm}$. To verify the possibility of HAN@SnO 2 as nanostructured current collectors, a 

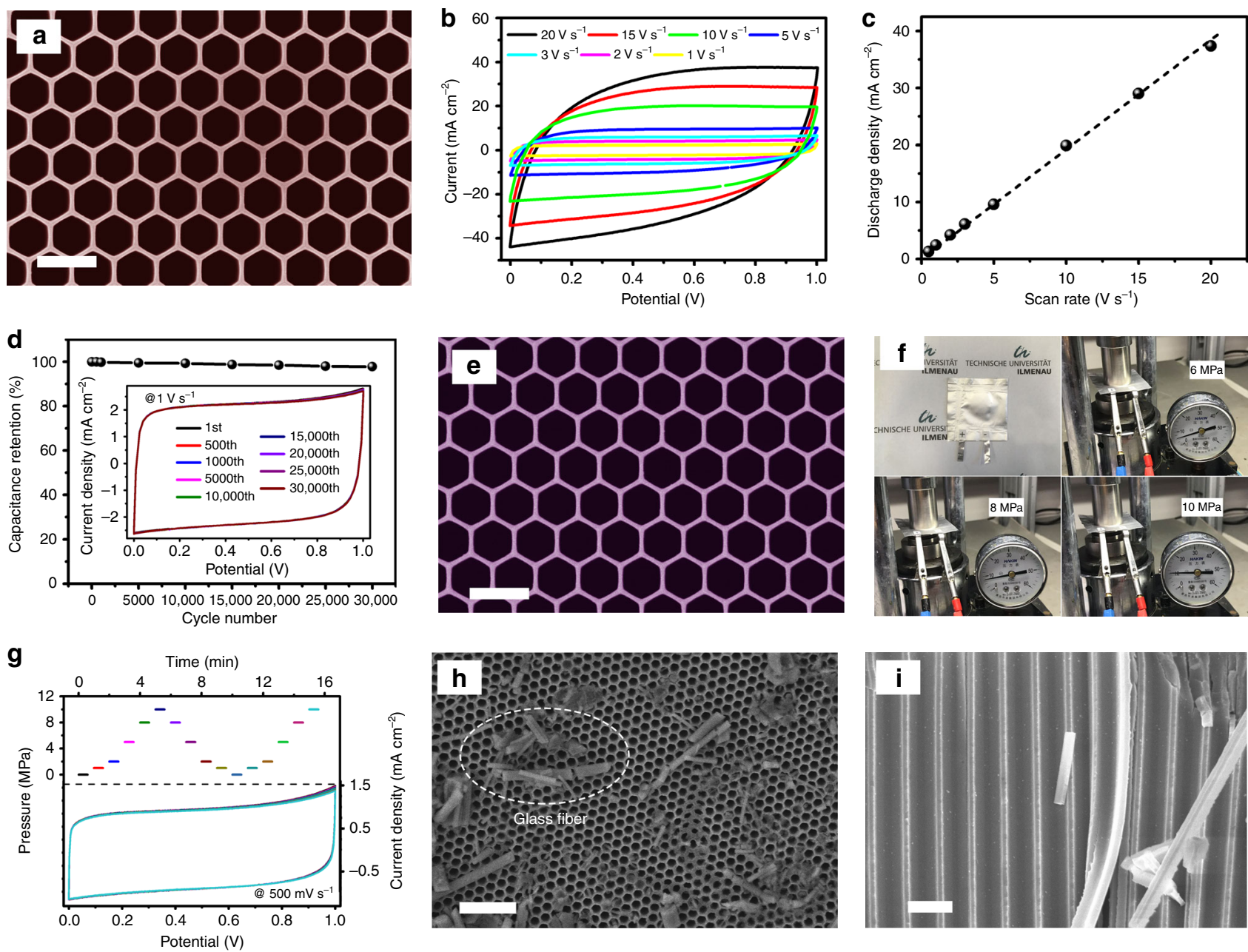

Fig. 2 Characterizations of $\mathbf{H A N} @ \mathrm{SnO}_{\mathbf{2}}$ as nanostructured current collectors. a Top-view SEM image of $\mathrm{HAN}_{\mathrm{N}} @ \mathrm{SnO}_{2}$. b CV curves of $\mathrm{HAN} @ S n \mathrm{C}_{2} / /$ $\mathrm{HAN} @ \mathrm{SnO}_{2}$ device at different scan rates. c The discharge current as function of the scan rates based on the $\mathrm{CV}$ curves of $\mathrm{HAN}_{\mathrm{N}} \mathrm{SnO} \mathrm{O}_{2} / / \mathrm{HAN} @ \mathrm{SnO}_{2}$

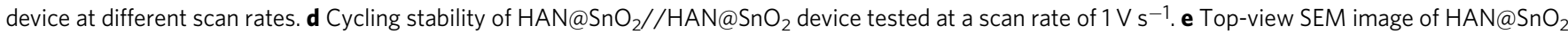
electrode after 30,000 CV cycles. f Photographs of $\mathrm{HAN} @ \mathrm{SnO}_{2} / / \mathrm{HAN} @ \mathrm{SnO}_{2}$ device tested under different mechanical extrusion pressure. $\mathbf{g}$ CV profiles of HAN@SnO $/ / / \mathrm{HAN} @ \mathrm{SnO}_{2}$ device measured at a scan rate of $500 \mathrm{mV} \mathrm{s}^{-1}$ under different mechanical extrusion pressure. $\mathbf{h}$ Top-view, and $\mathbf{i}$ crosssectional SEM image of $\mathrm{HAN} @ \mathrm{SnO}_{2}$ electrode after $\mathrm{CV}$ test under a mechanical extrusion pressure of $10 \mathrm{MPa}$, respectively. Scale bar: $500 \mathrm{~nm}$ (a, e); $2 \mu \mathrm{m}$ (h); $500 \mathrm{~nm}(\mathbf{i})$.

symmetric supercapacitor based on two HAN@SnO 2 electrodes, $\mathrm{HAN@SnO} / / / \mathrm{HAN} @ \mathrm{SnO}_{2}$, were assembled and characterized since $\mathrm{SnO}_{2}$ is also one kind of electroactive materials for supercapacitors. Rate performance of supercapacitors, especially under high scan rate, could indirectly reflect the ionic and electronic transport behavior of electrodes. The cyclic voltammetry (CV) curves of the device at different scan rates are shown in Fig. 2b, and all have a quasi-rectangular shape even at a high scan rate of $20 \mathrm{~V} \mathrm{~s}^{-1}$, which indicates the typical double-layer capacitive behavior of the device. Figure $2 c$ reveals the corresponding variation of the discharge current density at different scan rates. Clearly, the discharge currents keep a linear relationship upon scan rates nearly until $20 \mathrm{~V} \mathrm{~s}^{-1}$, suggesting the high instantaneous power characteristics of the device. The representative Nyquist plot of the device, and the corresponding expanded view at the high-frequency region, again reveals the capacitive behavior even at high frequencies that are attributed to the fully accessible surface area of the electrodes for electrolyte ions adsorption/ desorption (Supplementary Fig. 2). Moreover, the high-frequency semicircle reflects the small charge transfer resistance $\left(R_{c t}\right)$ of only $1.8 \Omega$ in HAN@SnO $2 / / \mathrm{HAN} @ \mathrm{SnO}_{2}$ device, also contributing to realize high-rate performance. Therefore, high-rate performance should be attributed not only to the rapid mass transport of ions but also to the efficient charge transport and collection in $\mathrm{HAN} @ \mathrm{SnO}_{2}$ nanoelectrodes during the ultrafast chargedischarge process ${ }^{21}$.

In addition, a nearly $98 \%$ of the initial performance was retained after continued 30,000 charge/discharge cycles at a scan rate of $1 \mathrm{~V} \mathrm{~s}^{-1}$ (Fig. 2d) and no obvious structural changes and/or damages can be found for the electrodes when comparing the SEM images of the HAN@SnO 2 electrodes before and after longtermed cycling (Fig. 2a, e, respectively). The high stability in both electrochemical performance and electrode structure should be attributed to the existence of the HAN in the nanoelectrodes to functionalize as mechanically robust keel. On the other hand, it is well-known that the mechanical extrusion is an essential step during the device assembly of supercapacitors and batteries ${ }^{14}$, however, at the same time it would generate a destructive impact on nanoelectrodes. For example, the collapse of nanostructures and then the block of ionic transport pathway will subsequently result in unexpectedly device performance degradation compared to the result of three-electrode configuration. Attributing to the high stiffness of $\mathrm{Al}_{2} \mathrm{O}_{3}$, the monolithic structure of $\mathrm{HAN}$ without structural defects over a large area and the high Young's modulus 
of the HAN, HAN@SnO ${ }_{2}$ electrodes are endowed with high compression strength to sufficiently withstand the mechanical extrusion during the device assembly without collapse or deformation of the nanoporous structure. As a result, $\mathrm{HAN@SnO}{ }_{2}$ electrodes could remain their initial integrated structure with vertically aligned nanoporous structure and finally, the HAN@SnO $2 / / \mathrm{HAN} @ \mathrm{SnO}_{2}$ device still works very well without deteriorating the capacitive behavior even under an applied mechanical extrusion pressure up to $10 \mathrm{MPa}$ (Fig. 2f, g). The constant CV profiles indicate that there is nearly no change in the ion-accessible surface area and the ion transport resistance under the continuous mechanical extrusion. Furthermore, the SEM images (Fig. 2h, i) reveal that the HAN@SnO 2 electrodes still remain the original nanoporous features after the electrochemical test under the continuous mechanical extrusion. Note that the residues in Fig. $2 \mathrm{~h}, \mathrm{i}$ is the residual glass fibers from a glass microfiber filter that was used as separator, and partials of the glass microfiber filter were damaged and fallen off during the disassembly of the HAN@SnO $2 / / \mathrm{HAN} @ S n O_{2}$ device. This result further reveals the excellent mechanical stability of the HAN that can efficiently sustain the mechanical extrusion pressure during the device assembly process to maintain the integrality of the nanoelectrodes. Overall, the excellent electrochemical performance and the superior structural stability verify the great capability of $\mathrm{HAN} @ \mathrm{SnO}_{2}$ as desirable nanostructured current collectors to design nanoelectrodes for batteries and supercapacitors.

Assembly and electrochemical performance of symmetric MSCs. Following the electrochemical characterization of HAN@SnO $\mathrm{S}_{2}$ as nanostructured current collectors, a layer of pseudocapacitive materials was further electrochemically deposited with HAN@SnO 2 as nanostructured current collectors to produce nanoelectrodes for MSCs, which are magnesium oxide $\left(\mathrm{MnO}_{2}\right)$ coated HAN@SnO $\left.\mathrm{HAN}_{2} @ \mathrm{HnO}_{2} @ \mathrm{MnO}_{2}\right)$ and polypyrrole (PPy) coated HAN@SnO 2 (HAN@SnO $2 @ P P y)$ nanoelectrodes, respectively. The pore depth of HAN in both two nanoelectrodes was $25 \mu \mathrm{m}$, and the mass loading of $\mathrm{MnO}_{2}$ and PPy was 0.65 and $1.32 \mathrm{mg} \mathrm{cm}^{-2}$, respectively. The detailed crosssectional SEM images of different sections (Supplementary Fig. 3) and the corresponding energy dispersive X-ray spectroscopy (EDX) elemental mapping results (Supplementary Figs. 4-5) clarify that the cell wall of $\mathrm{HAN} @ \mathrm{SnO}_{2}$ have been coated with PPy and $\mathrm{MnO}_{2}$, respectively. Thereafter, MSCs with symmetric device configuration were assembled through stacking two same HANbased nanoelectrodes separated by a glass microfiber filter and with $1.0 \mathrm{M} \mathrm{Na}_{2} \mathrm{SO}_{4}$ aqueous solution as electrolyte. Note that the footprint of all stacked MSCs is $0.5 \mathrm{~cm}^{2}$, which is equal to that of single electrode. Figure $3 \mathrm{a}$ is the $\mathrm{CV}$ curves of the assembled $\mathrm{HAN} @ \mathrm{SnO}_{2} @ \mathrm{MnO}_{2} / / \mathrm{HAN} @ \mathrm{SnO}_{2} @ \mathrm{MnO}_{2} \mathrm{MSCs}$ over a wide range of scan rates from 2 to $500 \mathrm{mV} \mathrm{s}^{-1}$ in a potential range of 0-0.8 V. Obviously, the CV curves at different scan rates exhibit a symmetrically rectangular shape, indicating an ideally capacitive behavior and fast charge-discharge characteristics of MSCs. The galvanostatic charge-discharge (GCD) curves of HAN@S$\mathrm{nO}_{2} @ \mathrm{MnO}_{2} / / \mathrm{HAN} @ \mathrm{SnO}_{2} @ \mathrm{MnO}_{2}$ MSCs at different current densities are shown in Fig. 3b. These charging curves are very symmetric to the discharge counterparts, again indicating the excellent capacitive behaviors in MSCs. When depositing $\mathrm{MnO}_{2}$, the layer thickness of $\mathrm{MnO}_{2}$ was kept the same in all HAN@S$\mathrm{nO}_{2} @ \mathrm{MnO}_{2}$ electrodes, thus electrodes with deeper HAN have higher $\mathrm{MnO}_{2}$ mass loading. Figure 3c illustrates the device areal capacitance of MSCs with different pore depth of original HAN and $\mathrm{MnO}_{2}$ mass loading as a function of scan rates. The device capacitance depends strongly on the pore depth of original HAN and the subsequent changes of $\mathrm{MnO}_{2}$ mass loading of HAN@S$\mathrm{nO}_{2} @ \mathrm{MnO}_{2}$ electrodes. For $\mathrm{HAN} @ \mathrm{SnO}_{2} @ \mathrm{MnO}_{2}$ electrodes consisting of $25-\mu \mathrm{m}$-pore-deep $\mathrm{HAN}$, the $\mathrm{MnO}_{2}$ mass loading was $0.65 \mathrm{mg} \mathrm{cm}^{-2}$, consequently resulting in highest device capacitance of $137 \mathrm{mF} \mathrm{cm}^{-2}$ at a scan rate of $2 \mathrm{mV} \mathrm{s}^{-1}\left(121 \mathrm{mF} \mathrm{cm}^{-2}\right.$ at a current density of $0.2 \mathrm{~mA} \mathrm{~cm}^{-2}$, Supplementary Fig. 6). Benefiting from the vertically aligned nanoporous structure features, these symmetric MSCs have good rate performance, i.e., the capacitance of MSCs based on $\mathrm{HAN} @ \mathrm{SnO}_{2} @ \mathrm{MnO}_{2}$ electrodes with $25-\mu \mathrm{m}$-deep HAN remains to be $47 \mathrm{mF} \mathrm{cm}^{-2}$ when the scan rate increasing from 10 to $2,000 \mathrm{mV} \mathrm{s}^{-1}$. Additionally, the HAN@SnO $2 @ P P y / / H A N @ S n O_{2} @ P P y$ MSCs have the similar electrochemical performance to that of $\mathrm{HAN} @ \mathrm{SnO}_{2} @ \mathrm{MnO}_{2} / /$ $\mathrm{HAN} @ \mathrm{SnO}_{2} @ \mathrm{MnO}_{2} \mathrm{MSCs}$ except the different operating potential window that is from -0.8 to $0 \mathrm{~V}$. Figure $3 \mathrm{~d}$, e is the $\mathrm{CV}$ and GCD curves of $\mathrm{HAN} @ \mathrm{SnO}_{2} @ P P y / / H A N @ S n \mathrm{O}_{2} @ P P y$ MSCs, respectively. The pore depth of original HAN in electrodes was 25 $\mu \mathrm{m}$ and the corresponding PPy mass loading was $1.32 \mathrm{mg} \mathrm{cm}^{-2}$, and in this case, the maximum device capacitance of HAN@S$\mathrm{nO}_{2} @ \mathrm{PPy} / / \mathrm{HAN} @ S n \mathrm{O}_{2} @ \mathrm{PPy} \mathrm{MSCs}$ reaches $124 \mathrm{mF} \mathrm{cm}^{-2}$ at a scan rate of $10 \mathrm{mV} \mathrm{s}^{-1}\left(158 \mathrm{mF} \mathrm{cm}^{-2}\right.$ at a current density of 0.2 $\mathrm{mA} \mathrm{cm}{ }^{-2}$, Supplementary Fig. 6).

By contrast,HAN@SnO $2 / / \mathrm{HAN} @ S n \mathrm{O}_{2}$ MSCs with the same footprint $\left(0.5 \mathrm{~cm}^{2}\right)$ were also assembled and characterized to further understand the role of $\mathrm{SnO}_{2}$ layer in $\mathrm{HAN} @ \mathrm{SnO}_{2}$ based pseudocapacitive electrodes. It can be concluded from Fig. $3 \mathrm{c}, \mathrm{f}$ that the negligible capacitance $\left(<4 \mathrm{mF} \mathrm{cm}^{-2}\right)$ of $\mathrm{HAN} @ \mathrm{SnO}_{2} / /$ $\mathrm{HAN} @ \mathrm{SnO}_{2} \mathrm{MSCs}$, in which the pore depth of HAN in all electrodes was $25 \mu \mathrm{m}$, suggests the function of $\mathrm{SnO}_{2}$ layer in $\mathrm{HAN} @ \mathrm{SnO}_{2}$ based pseudocapacitive electrodes mostly for charge transport rather than charge storage. Furthermore, electrochemical impendence spectroscopy (EIS) was performed in order to clearly understand the role of $\mathrm{HAN} @ \mathrm{SnO}_{2}$ as nanostructured current collectors. Figure $4 \mathrm{a}$ is the Nyquist plots of $\mathrm{HAN} @ \mathrm{SnO}_{2} / /$ $\mathrm{HAN} @ \mathrm{SnO}_{2}$ MSCs with different pore depth of original HAN (i.e., 5, 16 and $25 \mu \mathrm{m}$, respectively). All MSCs have very similar equivalent series resistances (ESR), however, there is a significant raise in $R_{c t}$. The gradually increased $R_{c t}$ should be the inevitable result arising from the limited electrical conductivity of $\mathrm{SnO}_{2}$, which is much lower than that of metals. The intrinsic electrical resistance of $\mathrm{SnO}_{2}$ leads the total resistance of $\mathrm{HAN} @ \mathrm{SnO}_{2} / /$ $\mathrm{HAN} @ \mathrm{SnO}_{2}$ MSCs to be progressively increased accompanying with HAN pore depth increase, and then consequently results in an increase in $R_{c t}$. With respect to $\mathrm{HAN} @ \mathrm{SnO}_{2} @ \mathrm{MnO}_{2} / /$ $\mathrm{HAN} @ \mathrm{SnO}_{2} @ \mathrm{MnO}_{2}$ and $\mathrm{HAN} @ \mathrm{SnO}_{2} @ \mathrm{PPy} / / \mathrm{HAN} @ \mathrm{SnO}_{2} @ \mathrm{PPy}$ MSCs (Fig. 4b, c, respectively), all exhibit similar Nyquist curves, including a semicircle in the high-frequency region and a nearly vertical line in the low-frequency region. In the high-frequency region, the diameters of the semicircle for $\mathrm{HAN} @ \mathrm{SnO}_{2} @ \mathrm{MnO}_{2} / /$ $\mathrm{HAN} @ \mathrm{SnO}_{2} @ \mathrm{MnO}_{2} \mathrm{MSCs}$ are bigger than those of HAN@S$\mathrm{nO}_{2} @ \mathrm{PPy} / / \mathrm{HAN} @ \mathrm{SnO}_{2} @ \mathrm{PPy} \mathrm{MSCs}$, indicating a higher $R_{c t}$ of $\mathrm{HAN} @ \mathrm{SnO}_{2} @ \mathrm{MnO}_{2} / / \mathrm{HAN} @ \mathrm{SnO}_{2} @ \mathrm{MnO}_{2} \mathrm{MSCs}$. Additionally, the higher $R_{c t}$ of $\mathrm{HAN} @ \mathrm{SnO}_{2} @ \mathrm{MnO}_{2} / / \mathrm{HAN} @ \mathrm{SnO}_{2} @ \mathrm{MnO}_{2}$ MSCs are also evidenced by the more obvious potential drops of GCD curves than those of $\mathrm{HAN} @ \mathrm{SnO}_{2} @ \mathrm{PPy} / / \mathrm{HAN} @ S-$ $\mathrm{nO}_{2} @ \mathrm{PPy} \mathrm{MSCs}$ (Fig. 3b, e). In addition, both HAN@S$\mathrm{nO}_{2} @ \mathrm{MnO}_{2} / / \mathrm{HAN} @ \mathrm{SnO}_{2} @ \mathrm{MnO}_{2}$ and $\mathrm{HAN} @ \mathrm{SnO}_{2} @ \mathrm{PPy} / /$ HAN@SnO $\mathrm{O}_{2} @ P P y$ MSCs have the similar ESR as those of HAN@SnO $2 / / \mathrm{HAN} @ \mathrm{SnO}_{2}$ MSCs. The similar ESR suggests the negligible influence on the series bulk resistance with the use of $\mathrm{HAN} @ \mathrm{SnO}_{2}$ as nanostructured current collectors. In addition, the


(Fig. 4c) could be attributed to the higher electrical conductivity of PPy than that of $\mathrm{MnO}_{2}$. Figure $4 \mathrm{~d}$ summarizes the $R_{c t}$ of all HAN-based MSCs. For $\mathrm{HAN} @ \mathrm{SnO}_{2} @ \mathrm{MnO}_{2} / / \mathrm{HAN} @ S-$ $\mathrm{nO}_{2} @ \mathrm{MnO}_{2}$ MSCs, the $R_{c t}$ are all higher than those of 

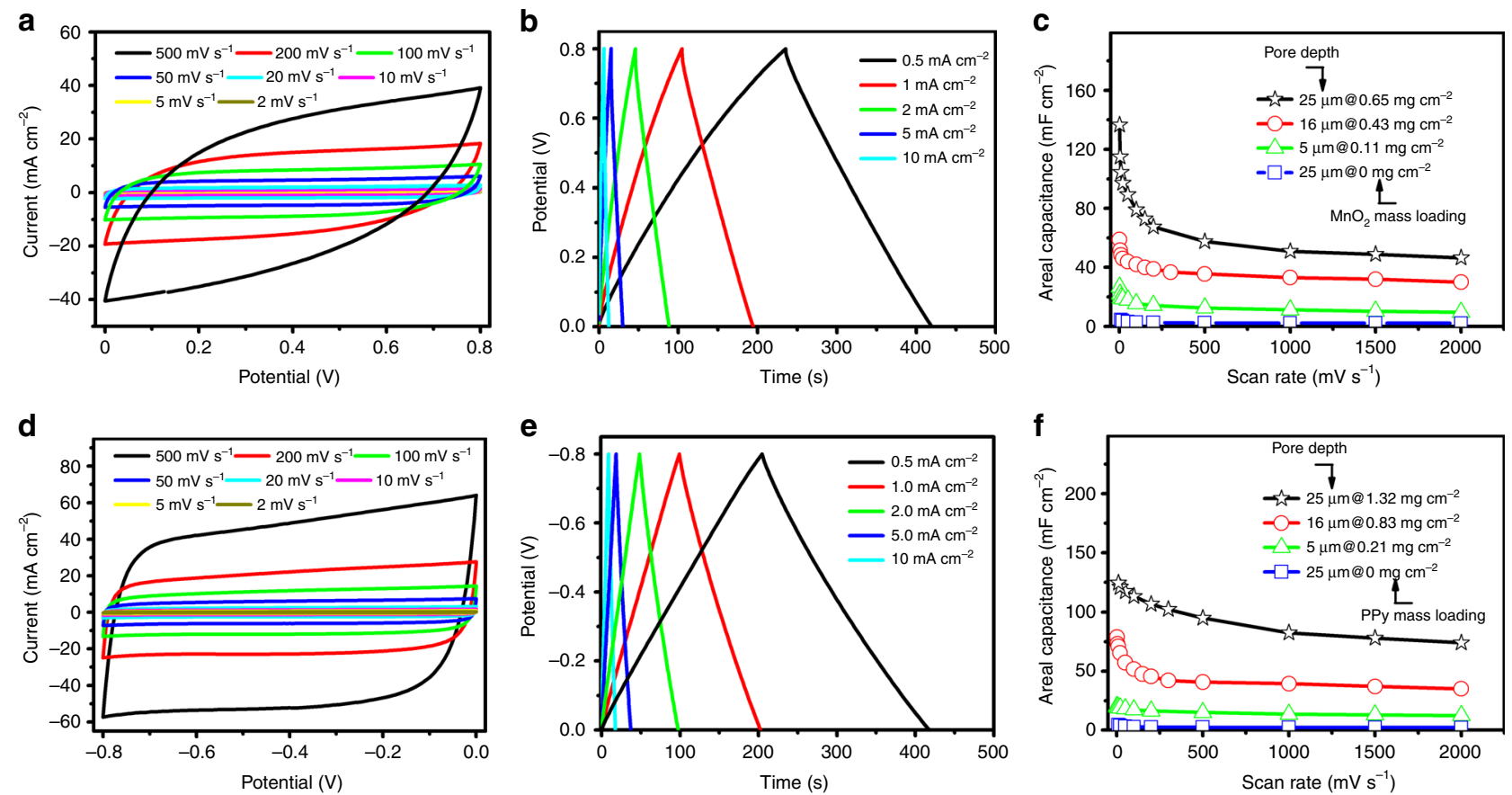

Fig. 3 Electrochemical performance of symmetric MSCs based on HAN-based nanoelectrodes. a CV curves at different scan rates, b GCD profiles at different current densities, and $\mathbf{c}$ device areal capacitance as a function of scan rates of $\mathrm{HAN} @ \mathrm{SnO}_{2} @ \mathrm{MnO}_{2} / / \mathrm{HAN}_{\mathrm{N}} @ \mathrm{SnO}_{2} @ \mathrm{MnO}_{2} \mathrm{MSC}$, respectively. $\mathbf{d}$ CV curves at different scan rates, e GCD profiles at different current densities, and $\mathbf{f}$ device areal capacitance as a function of scan rates of

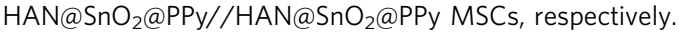

HAN@SnO $2 / / H A N @ \mathrm{HnO}_{2}$ MSCs. Besides the increased electrical resistance in $\mathrm{HAN} @ \mathrm{SnO}_{2}$ current collectors, the gradual raise in $R_{c t}$ of HAN@SnO $2 @ \mathrm{MnO}_{2} / / \mathrm{HAN} @ \mathrm{SnO}_{2} @ \mathrm{MnO}_{2} \mathrm{MSCs}$ should be due to the low intrinsic conductivity of $\mathrm{MnO}_{2}$. The low conductive $\mathrm{MnO}_{2}$ layer makes the charge transport in HAN@S$\mathrm{nO}_{2} @ \mathrm{MnO}_{2}$ electrodes mainly rely on the conductive $\mathrm{SnO}_{2}$ layer, which results in the exclusive pathway for charge transportation. On the contrary, the highly conductive PPy layer could not only store charges but also partially contribute to the charge transport for improving the charge transport efficiency in HAN@S$\mathrm{nO}_{2} @ \mathrm{PPy}$ electrodes, resulting in lower $R_{c t}$ of HAN@S$\mathrm{nO}_{2} @ \mathrm{PPy} / / \mathrm{HAN} @ \mathrm{SnO}_{2} @ \mathrm{PPy}$ MSCs than those in both $\mathrm{HAN} @ \mathrm{SnO}_{2} / / \mathrm{HAN} @ \mathrm{SnO}_{2}$ and $\mathrm{HAN} @ \mathrm{SnO}_{2} @ \mathrm{MnO}_{2} / / \mathrm{HAN} @ S-$ $\mathrm{nO}_{2} @ \mathrm{MnO}_{2}$ MSCs. Furthermore, fast ion transport at the interface between electrode and electrolyte could be evident by the inconspicuous Warburg region. In the low-frequency region (Supplementary Fig. 7), all HAN-based MSCs exhibit an almost vertical line, representing the promising permeability for electrolyte infiltration and ion diffusion to access the surface of pseudocapacitive materials, and to create more active sites for electrochemical reactions to store more charges.

Construction and performance evaluation of asymmetric MSCs. The areal energy density is directly proportional to the areal capacitance value and the square of the cell voltage. Nevertheless, the energy density of supercapacitors is restricted by the use of pseudocapacitive materials with a narrow potential window. An asymmetric device configuration affords the opportunity for the expansion of the operating potential window of pseudocapacitors, and subsequently accomplishes the enhanced energy and power densities. Asymmetric MSCs were therefore assembled by using $\mathrm{HAN} @ \mathrm{SnO}_{2} @ \mathrm{MnO}_{2}$ as positive electrode and HAN@SnO ${ }_{2} @ P P y$ as negative electrode. The two electrodes were stacked together with a glass microfiber filter as separator and $1.0 \mathrm{M} \mathrm{Na}_{2} \mathrm{SO}_{4}$ aqueous solution as electrolyte. As the aforementioned symmetric MSCs, the footprint of HAN@S$\mathrm{nO}_{2} @ \mathrm{MnO}_{2} / / \mathrm{HAN} @ \mathrm{SnO}_{2} @ \mathrm{PPy} \mathrm{MSCs}$ was also $0.5 \mathrm{~cm}^{2}$. Note that a charge balance between the two electrodes was accomplished by controlling the deposition time of $\mathrm{MnO}_{2}$ at the positive electrode and the thickness of the PPy film at the negative electrode. Figure $5 \mathrm{a}$ outlines the working potential windows of each symmetric MSCs individually, -0.8-0 V for $\mathrm{HAN} @ \mathrm{SnO}_{2} @ \mathrm{PPy} / /$ HAN@SnO $\mathrm{O}_{2} @ P P y \mathrm{MSC}$ and 0-0.8V for HAN@SnO $\mathrm{H}_{2} @ \mathrm{MnO}_{2} / /$ $\mathrm{HAN} @ \mathrm{SnO}_{2} @ \mathrm{MnO}_{2} \mathrm{MSCs}$, so that the asymmetric MSCs by integrating HAN@SnO $2 @ P P y$ and HAN@SnO ${ }_{2} @ \mathrm{MnO}_{2}$ into single MSCs will result in an increased operating cell voltage up to $1.6 \mathrm{~V}$. As shown in Fig. 5b, the asymmetric MSCs with $16-\mu \mathrm{m}-$ pore-deep HAN in all electrodes work efficiently in the range from 0.8 to $1.6 \mathrm{~V}$. Figure $5 \mathrm{c}, \mathrm{d}$ is the corresponding $\mathrm{CV}$ and GCD curves of asymmetric MSCs in a potential range of $0-1.6 \mathrm{~V}$, respectively. The nearly rectangular $\mathrm{CV}$ curves and the highly triangular charge-discharge profiles demonstrate an ideally capacitive behavior and the fast charge-discharge characteristics of the asymmetric MSCs. Particularly, the CV curves retain their rectangular shape without apparent distortions when increasing scan rates up to a high rate of $1000 \mathrm{mV} \mathrm{s}^{-1}$, indicating the extraordinary high-rate performance of asymmetric MSCs. And a highest device capacitance of $147 \mathrm{mF} \mathrm{cm}^{-2}$ has been achieved at a scan rate of $10 \mathrm{mV} \mathrm{s}^{-1}$ and still remain $80 \mathrm{mF} \mathrm{cm}^{-2}$ at the scan rate of $1000 \mathrm{mV} \mathrm{s}^{-1}$ (Supplementary Fig. 6). The maximum capacity of this device could reach $186 \mathrm{mF} \mathrm{cm}^{-2}$ at a current density of $0.2 \mathrm{~mA} \mathrm{~cm}^{-2}$ (Supplementary Fig. 8), and is one of the highest values among the reported MSCs (Supplementary Table 1). Moreover, the asymmetric MSCs have an excellent cyclic capability of $87 \%$ of its original capacity after continued 30,000 charge/discharge cycles tested at a current density of 20 $\mathrm{mA} \mathrm{cm}{ }^{-2}$ and with nearly $100 \%$ Coulombic efficiency (Fig. 5f). The slight performance degradation should be mainly due to $\mathrm{MnO}_{2}$, as evidenced by the obvious morphological changes after cycling (Supplementary Fig. 9). 
a

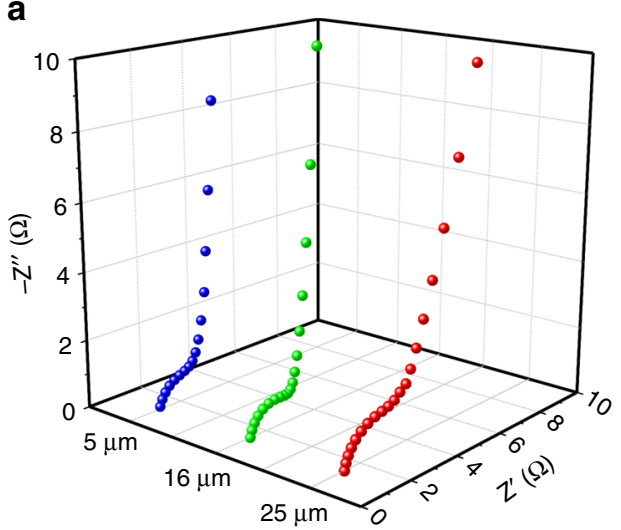

C

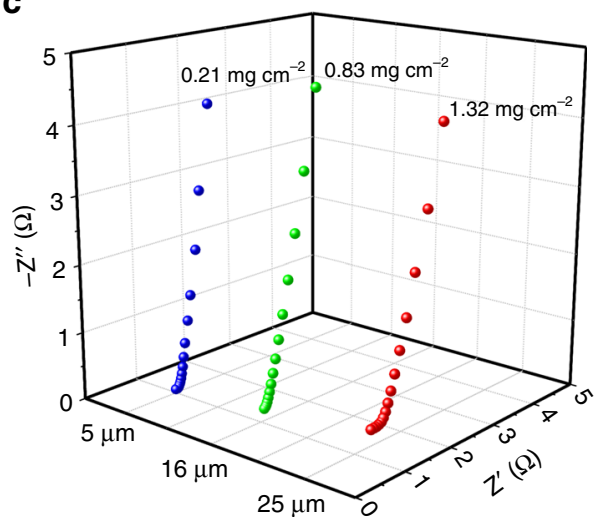

b

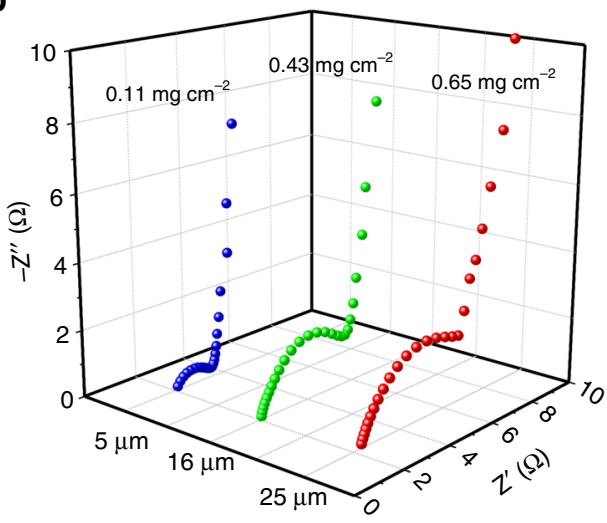

d

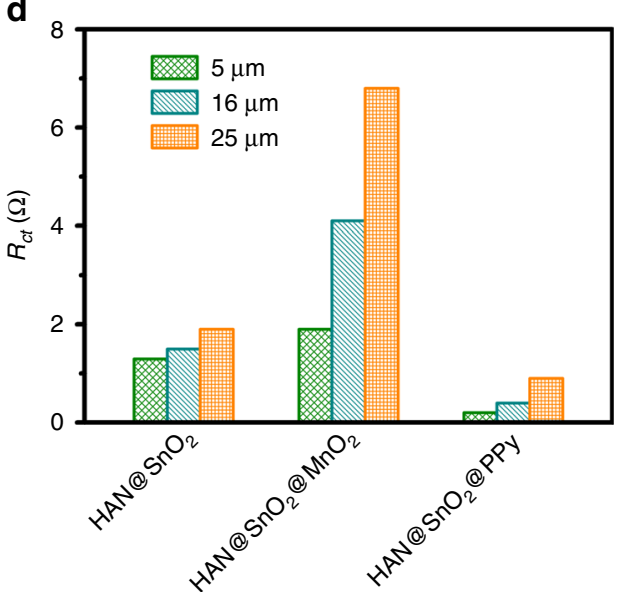

Fig. 4 Electrochemical impedance properties comparison. Nyquist plots of a $\mathrm{HAN} @ \mathrm{SnO}_{2} / / \mathrm{HAN} @ \mathrm{SnO}_{2}$, b $\mathrm{HAN}_{\mathrm{N}} @ \mathrm{SnO}_{2} @ \mathrm{MnO}_{2} / / \mathrm{HAN}_{\mathrm{N}} @ \mathrm{SnO}_{2} @ \mathrm{MnO}_{2}$, and $\mathbf{c H A N @ S n O} 2 @ P P y / / H A N @ S_{2} O_{2} @ P P y M S C s$ with different pore depths of HAN.d Comparison of the charge transport resistance $\left(R_{c t}\right)$ of different HAN-based MSCs.

When further replacing aqueous electrolyte with the ionic liquid electrolyte (1-ethyl-3-methylimidazolium bis(trifluoromethylsulfonyl)imide, EMIM-TFSI), the asymmetric MSCs can work efficiently in an enlarged potential range of 0-3.0 V (Fig. $5 \mathrm{~g}$, h). The distorted CV and GCD curves arise from the high viscosity and large charge transfer resistance of the electrolytes because of the large ion size of the ionic liquids ${ }^{22,23}$. The device capacitance reaches $128 \mathrm{mF} \mathrm{cm}^{-2}$ at a current density of $0.5 \mathrm{~mA}$ $\mathrm{cm}^{-2}$ (or $162 \mathrm{mF} \mathrm{cm}^{-2}$ at a scan rate of $10 \mathrm{mV} \mathrm{s}^{-1}$ ). When the current density is increased from 0.5 to $5 \mathrm{~mA} \mathrm{~cm}^{-2}$, the capacitance drops to $93 \mathrm{mF} \mathrm{cm}^{-2}$ ( $72 \%$ retention) and it recovers to $123 \mathrm{mF} \mathrm{cm}^{-2}$ (96\% retention) with the current density again being decreased to $0.5 \mathrm{~mA} \mathrm{~cm}^{-2}$ (Fig. 5i), revealing the excellent rate performance of the asymmetric MSCs. In addition, the asymmetric MSCs with ionic liquid electrolyte still exhibit remarkable cycling stability with $82.5 \%$ of initial capacitance at $20 \mathrm{~mA} \mathrm{~cm}^{-2}$ over a potential window of $0-3.0 \mathrm{~V}$ withstanding continued 10,000 cycles with high Coulombic efficiency of nearly $100 \%$ and slight decay in CV curves at $100 \mathrm{mV} \mathrm{s}^{-1}$ before and after cycling (Supplementary Fig. 10). Figure 6a presents the areal energy performance metrics of one representative HAN@S$\mathrm{nO}_{2} @ \mathrm{MnO}_{2} / / \mathrm{HAN} @ \mathrm{SnO}_{2} @ P P y$ asymmetric MSCs with EMIMTFSI ionic liquid electrolyte. The maximum capacitance of the MSCs reaches $128 \mathrm{mF} \mathrm{cm}^{-2}$ at a current density of $0.5 \mathrm{~mA} \mathrm{~cm}^{-2}$, and the peak energy and power densities are $160 \mu \mathrm{Wh} \mathrm{cm}^{-2}$ and $40 \mathrm{~mW} \mathrm{~cm}^{-2}$, respectively. Remarkably, the energy storage performance of the asymmetric MSCs with HAN-based nanoelectrodes is among the best comprehensive performance of the

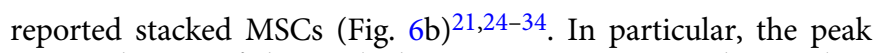
energy density of the stacked asymmetric MSCs in this work is roughly fourfold that of the carbide-derived-carbons (CDC) based stacked MSCs $\left(\sim 40 \mu \mathrm{Wh} \mathrm{cm}^{-2}\right)$ but with a similar peak power density ${ }^{24}$. Additionally, the areal energy density of the asymmetric MSCs with EMIM-TFSI electrolyte is even comparable with that of some state-of-the-art 3D micro-batteries but with much higher areal power density ${ }^{35,36}$.

\section{Discussion}

The insufficient energy of MSCs is their crucial flaw compared with micro-batteries and remains a major challenge to overcome. This work signifies the capability of the HAN as a promising nanostructuring platform to assemble pseudocapacitive materials toward rationally designing nanoelectrodes for MSCs with highenergy performance. In comparison with the conventional HMs, the HAN as a kind of microminiaturized HMs has the highest cell density, lower relative density, higher surface area enhancement factor, and excellent compressive performance. With such robust HAN as the keel, the as-prepared nanoelectrodes could possess vertically aligned and robustly stable nanoporous structure. And in contrast to nanoelectrodes design based on nanowires and nanotubes, there is no limit about the aspect ratio to sustain such vertically aligned nanoporous structure. Besides high surface area to provide abundant electroactive sites for surface Faradaic reactions, the vertically aligned nanoporous structure affords the smooth channels to favor the permeability for electrolyte 
a

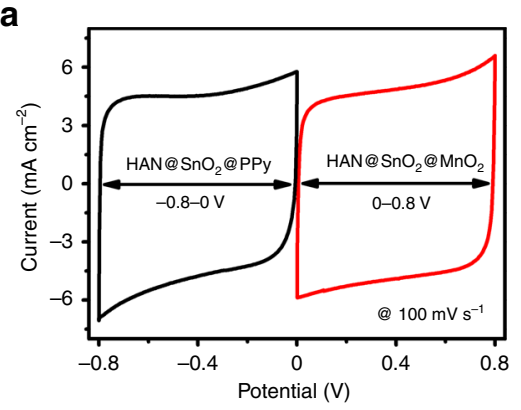

d

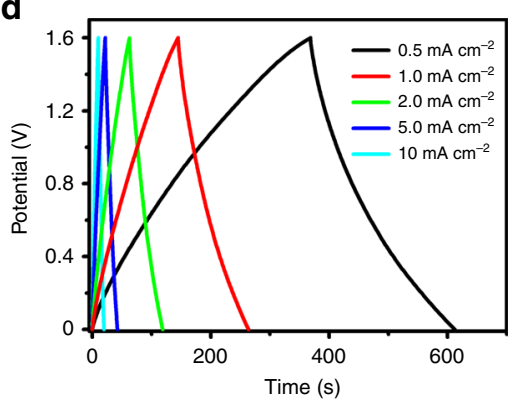

9

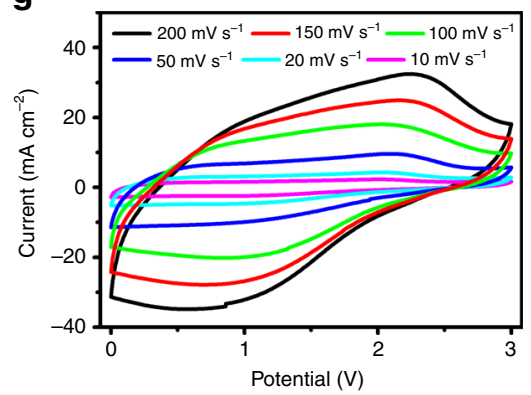

b

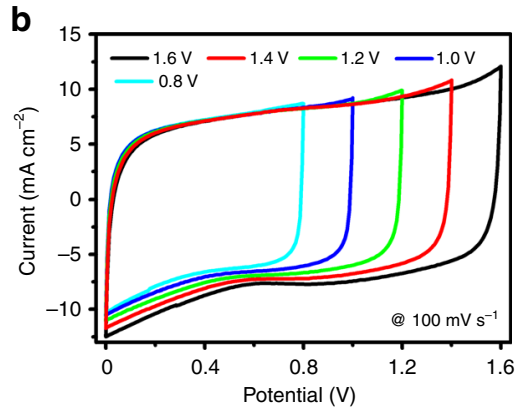

e

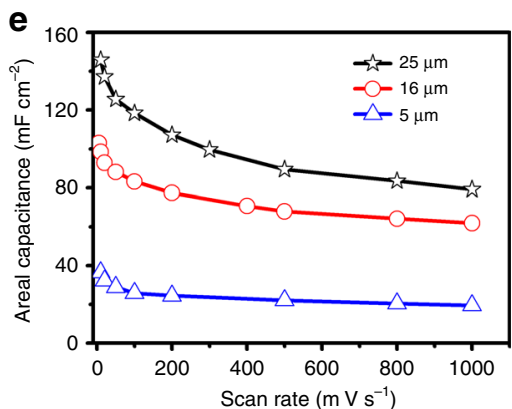

h

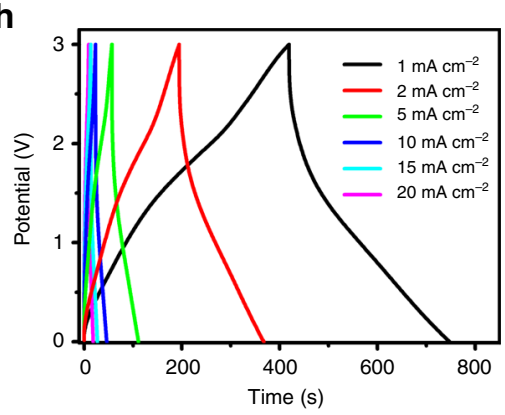

c

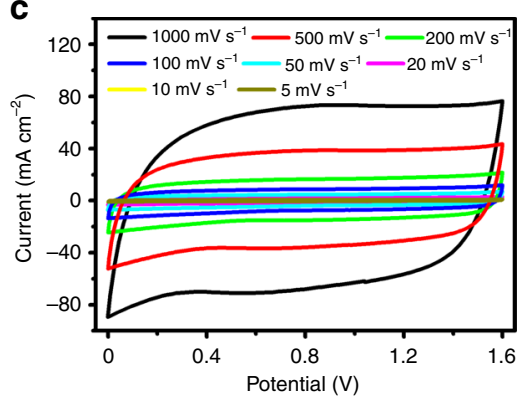

f
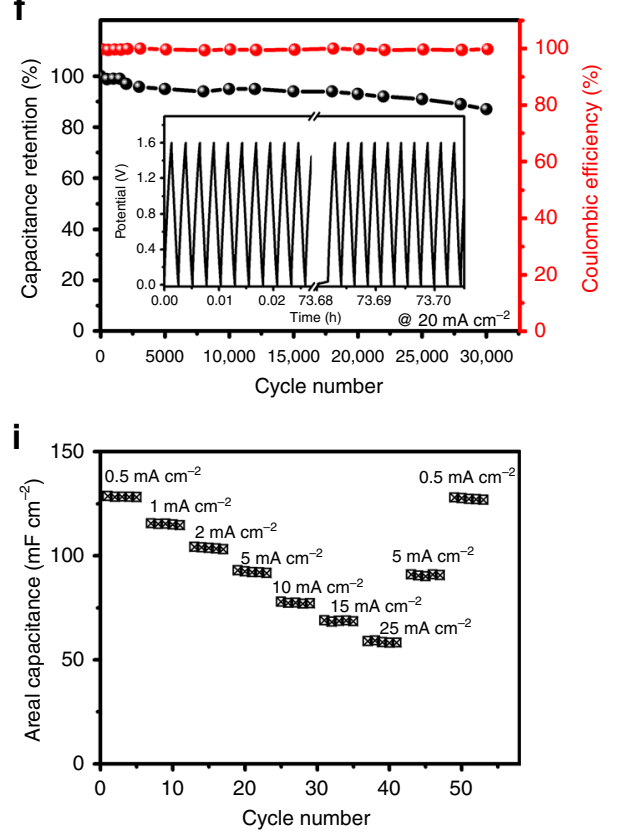

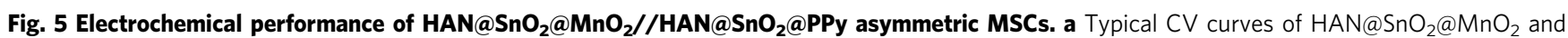
HAN@SnO $@$ PPy based symmetric MSCs, respectively, with $1.0 \mathrm{M} \mathrm{Na}_{2} \mathrm{SO}_{4}$ electrolyte. b CV curves within different potential ranges. c CV curves at different scan rates. $\mathbf{d}$ GCD profiles at different current densities. e Device areal capacitance as a function of current densities. $\mathbf{f}$ Cycling stability test at a scan rate of $20 \mathrm{~mA} \mathrm{~cm}^{-2} . \mathbf{g}$ CV curves at different scan rates, $\mathbf{h ~ G C D}$ profiles at different current densities, and $\mathbf{i}$ rate performance of asymmetric MSCs with EMIM-TFSI electrolyte, respectively.
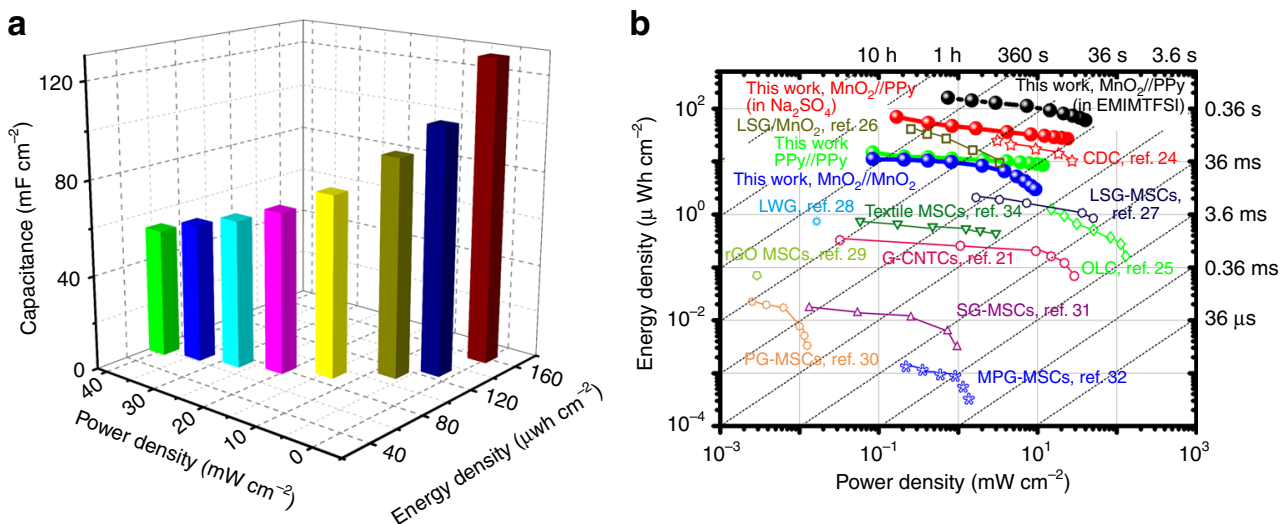

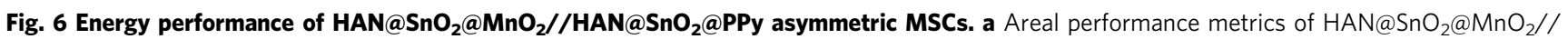
HAN@SnO $@ @ P P y$ asymmetric MSCs with EMIM-TFSI ionic liquid electrolyte. b Ragone plots of MSCs with HAN-based nanoelectrodes compared with some reported $\mathrm{MSCs}^{21,24-34}$ 
infiltration and ion diffusion to access the surface of pseudocapacitive materials, guaranteeing a high utilization efficiency of the pseudocapacitive materials. Taken together, the HAN-based nanoelectrodes design synergizes the effects of both effective ion migration and high electroactive surface area, thus enabling high and reversible capacitive behavior even at high charge-discharge rates. In the current HAN-based nanoelectrodes design, four strategies have been combined together into single MSCs aiming to achieve high-energy storage capability: (i) the utilization of pseudocapacitive materials with high specific capacitance in both positive and negative electrodes; (ii) the adoption of asymmetric device configuration to extend the operating potential window of MSCs; (iii) the application of ionic liquid electrolyte to further widen the operating potential window of MSCs; and more importantly, (iv) the prominent nanoelectrode architecture design based on HAN for both positive and negative electrodes. The combination of pseudocapacitive materials with unique nanoelectrodes architecture results in the increased areal capacitance with reduced footprint, meanwhile the adoption of asymmetric device configuration coupled with ionic liquid electrolyte helps to overcome the narrow operating potential window of pseudocapacitive materials. As a result, the asymmetric MSCs constructed with the HAN-based nanoelectrodes exhibit one of the most remarkable comprehensive areal device performance metrics.

We emphasize that nanoelectrode design with the robust HAN as the keel to assemble electroactive materials inherits the unique structural characteristics of the HMs and can be manipulated to achieve desired application requirements for electrochemical devices beyond MSCs. Our work opens up the ample opportunities for further expanding the application range of the HMs and also provides a paradigm about rationally designing nanostructures for various functional devices with new features and high performance.

\section{Methods}

Preparation of HAN. The HAN was fabricated through a nanoindentation anodization process, followed by a precisely controlled two-step chemical etching process. Firstly, a hexagonal patterns was generated onto the surface of aluminum foil by nanoindentation, then the aluminium foil was anodized in a $0.4 \mathrm{M}$ phosphoric acid $\left(\mathrm{H}_{3} \mathrm{PO}_{4}\right)$ aqueous solution at $160 \mathrm{~V}$ for different time. The temperature of the solution and the aluminium foil was kept at $10{ }^{\circ} \mathrm{C}$ during the anodization process. After anodization, the unanodized aluminum was etched by a mixture aqueous solution of $\mathrm{CuCl}_{2}$ (85 wt\%) and $\mathrm{HCl}(15 \mathrm{wt} \%)$. Thereafter a two-step chemical etching process was applied to obtain the HAN: (1) etching with a $5 \mathrm{wt} \% \mathrm{H}_{3} \mathrm{PO}_{4}$ solution at $60{ }^{\circ} \mathrm{C}$ to achieve an open-end membrane; (2) further etching with a $5 \mathrm{wt} \% \mathrm{H}_{3} \mathrm{PO}_{4}$ solution at $30^{\circ} \mathrm{C}$ to finally obtain HAN. The surface area enhancement factor $(A)$ for HAN was calculated by Eq. 1 :

$$
A=\frac{\frac{6}{\sqrt{3}} \times d \times h}{s^{2} \times \sin \theta}
$$

where $d$ and $h$ are corresponding to the cell diameter and depth of the cell, respectively, $s$ is the intercell distances, measured between the centers of the cells, and $\theta$ is the angle of the pattern in which the cells are positioned. For the typical HAN structure with cell depth of $25 \mu \mathrm{m}$, the specific values are $d=384 \mathrm{~nm}, h=25 \mu \mathrm{m}, s=$ $400 \mathrm{~nm}$ and $\theta=60^{\circ}$, respectively. Accordingly, the $A$ is calculated to be 240 .

Fabrication of HAN-based nanoelectrodes. The $\mathrm{HAN} @ \mathrm{SnO}_{2}$ substrate was produced by conformally depositing $\mathrm{SnO}_{2}$ on the surface of the as-prepared HAN at $250^{\circ} \mathrm{C}$ using an ALD system (Picosun, SUNALE R-150). The precursors were tin (IV) chloride $\left(\mathrm{SnCl}_{4}\right)$ for tin and ultrapure water for oxygen, respectively, and highpurity nitrogen was the carrier and purging gas. Specifically, each ALD cycle consisted of a $0.2 \mathrm{~s}$ pulse of $\mathrm{SnCl}_{4}$ and a $4 \mathrm{~s}$ purge of $\mathrm{N}_{2}$, followed by a $1 \mathrm{~s}$ pulse of $\mathrm{H}_{2} \mathrm{O}$ and an $8 \mathrm{~s}$ purge of $\mathrm{N}_{2}$, and this procedure was repeated 1500 times. The growth rate of $\mathrm{SnO}_{2}$ is estimated to be about $0.16 \AA$ per cycle. With the as-obtained $\mathrm{HAN} @ \mathrm{SnO}_{2}$ as the working electrodes, the HAN-based nanoelectrodes were fabricated through electrochemical deposition method. The HAN@SnO $@$ @Py electrode was prepared by electrochemical polymerization of PPy onto $\mathrm{HAN} @ \mathrm{SnO}_{2}$ substrate. The plating solution consisted of $0.1 \mathrm{M}$ pyrrole monomer (98\%) and 0.2 $\mathrm{M}$ oxalic acid, and the applied potential was $0.8 \mathrm{~V}$ (vs. $\mathrm{Ag} / \mathrm{AgCl})^{37}$. Likewise, the $\mathrm{HAN} @ \mathrm{SnO}_{2} @ \mathrm{MnO}_{2}$ electrode was fabricated by electrochemical deposition of $\mathrm{MnO}_{2}$ onto the HAN@SnO 2 substrate by using an electrolyte consisting of $50 \mathrm{mM}$ manganese acetate and $100 \mathrm{mM}$ sodium acetate with a constant current density of $1 \mathrm{~mA} \mathrm{~cm}^{-2}$. The active mass of the electrodes were determined according to Faraday's law and $100 \%$ charge efficiency was assumed, according to Eq. 2:

$$
m=\frac{Q M}{z F}
$$

where $Q$ is the charge passed during the electrochemical deposition process of active materials (i.e., $\mathrm{PPy} / \mathrm{MnO}_{2}$ ). And it is worth noting that the charge is precisely adjust here in order to achieve the same layer thickness of active materials for HAN@SnO $\mathrm{S}_{2}$ with different cell depth. $M$ is the molar mass of the active electrode material $\left(M_{\mathrm{MnO} 2}=86.9 \mathrm{~g} \mathrm{~mol}^{-1} ; M_{\mathrm{py}}=65.09 \mathrm{~g} \mathrm{~mol}^{-1}\right), F$ the Faraday constant and $z$ the number of transferred electrons per active electrode atom $(z=2$ for $\mathrm{MnO}_{2}$ and PPy deposition).

Apparatus for characterizations. The surface morphologies and microstructures of the electrodes were characterized using scanning electron microscopy (ZEISS AURIGA) equipped with an EDX detector. Cyclic voltammetry (CV), galvanostatic charge-discharge (GCD), electrochemical impedance spectroscopy (EIS) measurements, and cycling performance measurements were conducted with a Potentiostat (BioLogic, VSP). Nanoindentation was conducted with the Triboindenter (Hysitron) equipped with a Berkovich diamond indenter with an approximately 600 -nm-radius.

Electrochemical measurements and calculation of the electrochemical performances. All the electrochemical measurements were carried out in a two-electrode configuration with $1.0 \mathrm{M} \mathrm{Na}_{2} \mathrm{SO}_{4}$ aqueous electrolyte and a glass microfiber filter (Whatman, GF/B) as separator as well as 1-ethyl-3-methylimidazolium bis(trifluoromethylsulfonyl)imide (EMIM-TFSI) ionic liquid electrolyte ( $1 \mathrm{M}$ in acetonitrile). The CV curves were collected with various scan rates of 5 to $2000 \mathrm{mV} \mathrm{s}^{-1}$, and the GCD curves were obtained at current densities of $0.2,0.5,1,2,5,10,15,20$ and $25 \mathrm{~mA} \mathrm{~cm}^{-2}$. The EIS measurement was performed with a frequency range from $100 \mathrm{MHz}$ to $10 \mathrm{mHz}$ and a $5 \mathrm{mV}$ AC amplitude.

The capacitance of the device $C_{G C D}\left(\mathrm{mF} \mathrm{cm}^{-2}\right)$ is determined from the GCD profiles based on Eq. 3:

$$
C_{\mathrm{GCD}}=\frac{I \times \Delta t}{A \times \Delta V}
$$

where $\Delta \mathrm{t}(\mathrm{s})$ is the discharge time, $I(\mathrm{~mA})$ is the discharge current, $A\left(\mathrm{~cm}^{2}\right)$ is tota footprint area of device, and $\Delta \mathrm{V}(\mathrm{V})$ is the voltage window.

The device capacitance $C_{C V}\left(\mathrm{mF} \mathrm{cm}^{-2}\right)$ can also be calculated from $\mathrm{CV}$ curves based on Eq. 4:

$$
C_{\mathrm{CV}}=\frac{\int^{I \mathrm{dV}}}{v \times \Delta V \times A}
$$

where $I(\mathrm{~A})$ is the response current and $v\left(\mathrm{~V} \mathrm{~s}^{-1}\right)$ is the potential scan rate.

With GCD plots, the energy density $\left(E\right.$, unit: $\left.\mu \mathrm{Wh} \mathrm{cm}^{-2}\right)$ and power density $(P$, unit: $\mathrm{mW} \mathrm{cm}^{-2}$ ) of the device were calculated by Eqs. 5 and 6:

$$
\begin{gathered}
E=0.5 \times C \times \Delta V^{2} \\
P=\frac{E}{\Delta t}
\end{gathered}
$$

where $C\left(\mathrm{mF} \mathrm{cm}^{-2}\right)$ is the areal capacitance of the device, $\Delta \mathrm{t}(\mathrm{s})$ is the discharge time.

\section{Date availability}

The data that support the findings of this study are available from the corresponding authors on reasonable request.

Received: 22 April 2019; Accepted: 13 December 2019; Published online: 15 January 2020

\section{References}

1. Gibson, L. J. \& Ashby, M. F. Cellular Solids: Structure and Properties. (Cambridge Univ. Press, 1999).

2. Kreutzer, M. T., Kapteijn, F., Moulijn, J. A. \& Heiszwolf, J. J. Multiphase monolith reactors: chemical reaction engineering of segmented flow in microchannels. Chem. Eng. Sci. 60, 5895-5916 (2005).

3. Cybulski, A. \& Moulijn, J. A. Monoliths in heterogeneous catalysis. Catal. Rev. Sci. Eng. 36, 179-270 (1994).

4. Avila, P., Montes, M. \& Miró, E. E. Monolithic reactors for environmental applications: a review on preparation technologies. Chem. Eng. J. 109, 11-36 (2005)

5. Williams, J. L. Monolith structures, materials, properties and uses. Catal. Today 69, 3-9 (2001). 
6. Guo, Y. et al. Robust 3-D configurated metal oxide nano-array based monolithic catalysts with ultrahigh materials usage efficiency and catalytic performance tunability. Nano Energy 2, 873-881 (2013).

7. Ren, Z. et al. Monolithically integrated spinel $\mathrm{M}_{\mathrm{x}} \mathrm{Co}_{3-\mathrm{x}} \mathrm{O}_{4}(\mathrm{M}=\mathrm{Co}, \mathrm{Ni}, \mathrm{Zn})$ nanoarray catalysts: scalable synthesis and cation manipulation for tunable low-temperature $\mathrm{CH}_{4}$ and $\mathrm{CO}$ oxidation. Angew. Chem. Int. Ed. 53, 7223-7227 (2014).

8. Zhao, H., Zhou, M., Wen, L. \& Lei, Y. Template-directed construction of nanostructure arrays for highly-efficient energy storage and conversion. Nano Energy 13, 790-813 (2015).

9. Aricò, A. S., Bruce, P., Scrosati, B., Tarascon, J.-M. \& Van Schalkwijk, W Nanostructured materials for advanced energy conversion and storage devices. Nat. Mater. 4, 366-377 (2005).

10. Manthiram, A., Murugan, A. V., Sarkar, A. \& Muraliganth, T. Nanostructured electrode materials for electrochemical energy storage and conversion. Energy Environ. Sci. 1, 621-638 (2008).

11. Li, Y., Fu, Z. Y. \& Su, B. L. Hierarchically structured porous materials for energy conversion and storage. Adv. Funct. Mater. 22, 4634-4667 (2012).

12. Thompson, G. \& Wood, G. Porous anodic film formation on aluminium. Nature 290, 230 (1981).

13. Li, G. et al. Synthesis of biomorphic zeolite honeycomb monoliths with 16000 cells per square inch. J. Mater. Chem. 19, 8372-8377 (2009).

14. Cannarella, J. \& Arnold, C. B. Stress evolution and capacity fade in constrained lithium-ion pouch cells. J. Power Sources 245, 745-751 (2014).

15. Fukushima, M. \& Yoshizawa, Y.-i Fabrication of highly porous honeycomb shaped mullite-zirconia insulators by gelation freezing. Adv. Powder Technol. 27, 908-913 (2016).

16. Yu, Z.-L. et al. Bioinspired polymeric woods. Sci. Adv. 4, eaat7223 (2018).

17. Zheng, X. et al. Ultralight, ultrastiff mechanical metamaterials. Science 344, 1373-1377 (2014)

18. Bauer, J., Hengsbach, S., Tesari, I., Schwaiger, R. \& Kraft, O. High-strength cellular ceramic composites with 3D microarchitecture. Proc. Natl Acad. Sci. USA 111, 2453-2458 (2014).

19. Schaedler, T. A. et al. Ultralight metallic microlattices. Science 334, 962-965 (2011).

20. Li, T. et al. Anisotropic, lightweight, strong, and super thermally insulating nanowood with naturally aligned nanocellulose. Sci. Adv. 4, eaar3724 (2018).

21. Lin, J. et al. 3-dimensional graphene carbon nanotube carpet-based microsupercapacitors with high electrochemical performance. Nano Lett. 13, 72-78 (2012).

22. Kim, T., Jung, G., Yoo, S., Suh, K. S. \& Ruoff, R. S. Activated graphene-based carbons as supercapacitor electrodes with macro-and mesopores. ACS Nano 7, 6899-6905 (2013).

23. Zhang, F. et al. A high-performance supercapacitor-battery hybrid energy storage device based on graphene-enhanced electrode materials with ultrahigh energy density. Energy Environ. Sci. 6, 1623-1632 (2013).

24. Huang, P. et al. On-chip and freestanding elastic carbon films for microsupercapacitors. Science 351, 691-695 (2016)

25. Pech, D. et al. Ultrahigh-power micrometre-sized supercapacitors based on onion-like carbon. Nat. Nanotechnol. 5, 651-654 (2010).

26. El-Kady, M. F. et al. Engineering three-dimensional hybrid supercapacitors and microsupercapacitors for high-performance integrated energy storage. Proc. Natl Acad. Sci. USA 112, 4233-4238 (2015).

27. El-Kady, M. F. \& Kaner, R. B. Scalable fabrication of high-power graphene micro-supercapacitors for flexible and on-chip energy storage. Nat. Commun. 4, 1475 (2013).

28. Gao, W. et al. Direct laser writing of micro-supercapacitors on hydrated graphite oxide films. Nat. Nanotechnol. 6, 496-500 (2011).

29. Niu, Z. et al. All-solid-state flexible ultrathin micro-supercapacitors based on graphene. Adv. Mater. 25, 4035-4042 (2013).

30. Xiao, H. et al. One-step device fabrication of phosphorene and graphene interdigital micro-supercapacitors with high energy density. ACS Nano 11, 7284-7292 (2017).

31. $\mathrm{Wu}, \mathrm{Z}$.-S. et al. Bottom-up fabrication of sulfur-doped graphene films derived from sulfur-annulated nanographene for ultrahigh volumetric capacitance micro-supercapacitors. J. Am. Chem. Soc. 139, 4506-4512 (2017).
32. Wu, Z. S., Parvez, K., Feng, X. \& Müllen, K. Graphene-based in-plane microsupercapacitors with high power and energy densities. Nat. Commun. 4, 2487 (2013).

33. Shen, K., Ding, J. \& Yang, S. 3D printing quasi-solid-state asymmetric microsupercapacitors with ultrahigh areal energy density. Adv. Energy Mater. 8, 1800408 (2018).

34. $\mathrm{Pu}, \mathrm{X}$. et al. Wearable textile-based in-plane microsupercapacitors. Adv. Energy Mater. 6, 1601254 (2016).

35. Pikul, J. H., Zhang, H. G., Cho, J., Braun, P. V. \& King, W. P. High-power lithium ion microbatteries from interdigitated three-dimensional bicontinuous nanoporous electrodes. Nat. Commun. 4, 1732 (2013).

36. Ning, H. et al. Holographic patterning of high-performance on-chip 3D lithium-ion microbatteries. Proc. Natl Acad. Sci. USA 112, 6573-6578 (2015).

37. Grote, F. \& Lei, Y. A complete three-dimensionally nanostructured asymmetric supercapacitor with high operating voltage window based on PPy and $\mathrm{MnO}_{2}$. Nano Energy 10, 63-70 (2014).

\section{Acknowledgements}

The authors gratefully acknowledge the support from German Research Foundation (DFG: LE 2249/4-1 and LE 2249/5-1), as well as financial support for Long Liu from the China Scholarship Council (CSC).

\section{Author contributions}

Zh. L and Lo. L contributed equally to this work. Y.L. supervised the project. The concept was conceived by H.Z. and Y.L. Zh. L, Lo. L and H.Z. were involved in the fabrication and related characterizations. Zh. L, Lo. L, S.C. and Le. L performed the electrochemical experiments and data analysis under the guidance of H.Z., F.L., Zh. L, J.K. and Y.L. H.Z and Y.L. wrote the paper with the assistance of F.L., Y.Z. and J.K.

\section{Competing interests}

The authors declare no competing interests.

\section{Additional information}

Supplementary information is available for this paper at https://doi.org/10.1038/s41467 019-14170-6.

Correspondence and requests for materials should be addressed to H.Z., F.L., Z.L. or Y.L.

Peer review information Nature Communications thanks the anonymous reviewer(s) for their contribution to the peer review of this work. Peer reviewer reports are available.

Reprints and permission information is available at http://www.nature.com/reprints

Publisher's note Springer Nature remains neutral with regard to jurisdictional claims in published maps and institutional affiliations.

Open Access This article is licensed under a Creative Commons Attribution 4.0 International License, which permits use, sharing, adaptation, distribution and reproduction in any medium or format, as long as you give appropriate credit to the original author(s) and the source, provide a link to the Creative Commons license, and indicate if changes were made. The images or other third party material in this article are included in the article's Creative Commons license, unless indicated otherwise in a credit line to the material. If material is not included in the article's Creative Commons license and your intended use is not permitted by statutory regulation or exceeds the permitted use, you will need to obtain permission directly from the copyright holder. To view a copy of this license, visit http://creativecommons.org/ licenses/by/4.0/.

(c) The Author(s) 2020 